\title{
The Rod Photoreceptor-Specific Nuclear Receptor Nr2e3 Represses Transcription of Multiple Cone-Specific Genes
}

\author{
Jichao Chen, ${ }^{1}$ Amir Rattner, ${ }^{1}$ and Jeremy Nathans ${ }^{1,2,3,4}$ \\ Departments of ${ }^{1}$ Molecular Biology and Genetics, ${ }^{2}$ Neuroscience, and ${ }^{3}$ Ophthalmology and ${ }^{4}$ Howard Hughes Medical Institute, Johns Hopkins University \\ School of Medicine, Baltimore, Maryland 21205
}

\begin{abstract}
This study addresses one genetic regulatory mechanism that establishes the distinct identities of rod and cone photoreceptors. Previous work has shown that mutations in either humans or mice in the gene coding for photoreceptor-specific nuclear receptor Nr2e3 cause a progressive retinal degeneration characterized by increased numbers of short-wave cones. In the present work, we have examined the cellular and developmental pattern of Nr2e3 protein localization in mammals and fish, identified an optimal Nr2e3 DNA-binding site using cycles of binding to recombinant $\mathrm{Nr} 2 \mathrm{e} 3$, characterized the transcriptional activity of wild type and one of the disease-associated point mutations in $N r 2 e 3$ in transfected cells, and characterized the transcriptional defects in the naturally occurring $N r 2 e 3$ mutant $(r d 7)$ mouse. These experiments indicate that in the mature vertebrate retina $N r 2 e 3$ is expressed exclusively in rods, that expression of $N r 2 e 3$ is one of the earliest events in the pathway of rod-specific photoreceptor development, and that Nr2e3 functions, either directly or indirectly, as a repressor of cone-specific genes in rod photoreceptor cells.
\end{abstract}

Key words: retina; rod photoreceptor; gene expression; nuclear receptor; retinal disease; vision; development

\section{Introduction}

The rod and cone photoreceptors of the vertebrate retina differ in a variety of respects (Rodieck, 1998). Rods are specialized for vision at low light levels, whereas cones are specialized for vision at high light levels, and they also mediate color vision. Although rods and cones share a common signaling pathway for phototransduction, most of the signaling proteins are coded by distinct rod- and cone-specific genes. Mammalian rods exit their terminal mitosis and develop later than cones, and they contact a distinct type of bipolar cell, the rod bipolar. In most mammals, rods greatly outnumber cones, and cones are generally confined to only the outermost layer of photoreceptor cells. In some vertebrates, including primates and birds, cones are found at high density in a specialized region of the retina, the fovea or visual pit, which mediates high-acuity vision. Finally, most vertebrate retinas contain only a single homogeneous class of rods but multiple classes of cones that differ with respect to their visual pigment content, spectral sensitivity, synaptic contacts, and abundance and distribution across the retina.

How do rod and cone photoreceptors develop the distinct programs of gene expression that determine their separate identities? The first steps in answering this question have come from the identification of several transcription factors that control

Received Aug. 30, 2004; revised Nov. 9, 2004; accepted Nov. 12, 2004.

This work was supported by the National Eye Institute and the Howard Hughes Medical Institute. We thank Dr. Peter MacLeish, Dr. James Fadool, Dr. Scott Fraser, Dr. James Hurley, Wenqin Luo, Dr. David Manglesdorf, Dr. Robert Molday, Dr. Francisco Murillo, Wenyi Wang, and Dr. Yanshu Wang for advice and/or materials and Dr. Thomas Rotolo, Dr. Chunqiao Liu, and two anonymous referees for helpful comments on this manuscript.

Correspondence should be addressed to Dr. Jeremy Nathans, Johns Hopkins University School of Medicine, 805 Preclinical Teaching Building, 725 North Wolfe Street, Baltimore, MD 21205. E-mail: jnathans@jhmi.edu.

DOI:10.1523/JNEUROSCI.3571-04.2005

Copyright $\odot 2005$ Society for Neuroscience $\quad$ 0270-6474/05/250118-12\$15.00/0 photoreceptor-specific gene expression. Crx is a homeobox gene that is expressed in both rods and cones and is required for the expression of a variety of photoreceptor-specific genes (Chen et al., 1997; Furukawa et al., 1997). Crx mutations cause photoreceptor degeneration in both mice and humans (Freund et al., 1997; Swain et al., 1997; Furukawa et al., 1999). Nrl is expressed in rods and encodes a leucine zipper transcription factor. Targeted deletion of mouse $\mathrm{Nrl}$ causes rod photoreceptors to acquire many of the molecular characteristics of short-wave cones (also referred to as UV or S-cones) (Mears et al., 2001). In humans, Nrl point mutations are associated with retinal dystrophy (Bessant et al., 1999). In the mouse, thyroid hormone receptor $\beta 2$ is required for the development of middle wave cones (also referred to as green or M-cones); in its absence, $\mathrm{S}$-cones replace the M-cones (Ng et al., 2001).

Nuclear receptor Nr2e3/photoreceptor cell-specific nuclear receptor, the focus of this study, was initially identified as an orphan nuclear receptor expressed specifically in ocular tissues (Chen et al., 1999; Kobayashi et al., 1999). Although the cellular localization of $\mathrm{Nr} 2 \mathrm{e} 3$ transcripts was initially a matter of dispute, it is now generally accepted that these transcripts are confined to photoreceptor cells (Kobayashi et al., 1999; Akhmedov et al., 2000; Haider et al., 2000, 2001). In humans, NR2E3 mutations cause enhanced S-cone syndrome, an autosomal recessive disorder in which a progressive degeneration of rod photoreceptors is accompanied by an increase in the relative numbers of S-cones and a markedly enhanced sensitivity to short-wave light (Haider et al., 2000). Mutations in NR2E3 have also been found in patients with Goldmann-Favre syndrome and clumped pigmentary retinal degeneration (Gerber et al., 2000; Sharon et al., 2003). A naturally occurring recessive $\mathrm{Nr} 2 \mathrm{e} 3$ mutation was identified in the $r d 7$ mouse as the cause of progressive photoreceptor degen- 
eration associated with retinal folds and an $\sim 1.5-2$ fold increase in the number of S-cones (Akhmedov et al., 2000; Haider et al., 2001; Yanagi et al., 2002). Among the major unanswered questions are the identities of the genes that are regulated by $\mathrm{Nr} 2 \mathrm{e} 3$ and the developmental context of that regulation.

In the present work, we have (1) examined the cellular and developmental pattern of $\mathrm{Nr} 2 \mathrm{e} 3$ protein localization in mammals and fish, (2) identified an optimal Nr2e3 DNA-binding site using cycles of binding to recombinant Nr2e3, (3) characterized the transcriptional activity of wild type and one of the diseaseassociated point mutations in Nr2e3 in transfected cells, and (4) characterized the transcriptional defects in the $r d 7$ mouse. These experiments indicate that $\mathrm{Nr} 2 e 3$ is expressed exclusively in rods in the mature retina, that expression of $\mathrm{Nr} 2 e 3$ is one of the earliest events in the pathway of rod photoreceptor development, and that Nr2e 3 functions as a repressor of cone-specific genes in rod photoreceptor cells.

\section{Materials and Methods}

Plasmids. The human and mouse Nr2e3 coding regions were PCRamplified from human retina and mouse eye cDNA libraries, respectively. The GAL4 DNA-binding domain (amino acids 1-147) from pCMX/GAL-L/mRXRa (a gift from Dr. David Mangelsdorf, University of Texas Southwestern Medical Center, Dallas, TX) was cloned into the SmaI and EcoRI sites of pRK5-SK to obtain pRK5-SK-GAL. The ligandbinding domain (amino acids 126-410) of human Nr2e3 (hNr2e3) was cloned into the EcoRI and HindIII sites of pRK5-SK-GAL4. PCR mutagenesis was performed according to standard protocols. Fourteen copies of the GAL4 upstream activating sequence (UAS) site from pBUASE1BlynGFP (green fluorescent protein) (a gift from Dr. Scott Fraser, California Institute of Technology, Pasadena, CA), and either two or four copies of the optimal Nr2e3-binding site (AAGGTCAAAGATCA) (this study) in either orientation were cloned into the HindIII site of pTK-Luc (a gift from Dr. David Mangelsdorf).

Cloning of the zebrafish Nr2e3 ortholog. One zebrafish expressed sequence tag (EST; wz2916.2) with significant homology to hNr2e3 was identified by a BLAST search of the zebrafish EST database at Washington University (www.zfish.wustl.edu/) and used as a query to search the zebrafish genome database from the Sanger Center sequencing project (danio.mgh.harvard.edu/ blast/blast_grp.html). One bacterial artificial chromosome clone (zKp91C1) was retrieved and analyzed using Genescan (genes.mit.edu/GENSCAN.html) and Spidey (www.ncbi.nlm.nih.gov/spidey/index.html). Based on this analysis, the predicted coding region of zebrafish Nr2e3 (zNr2e3) was PCR-amplified from an adult zebrafish retina cDNA library (a gift from Dr. James Hurley, University of Washington, St. Louis, MO). The complete $5^{\prime}$ end of zNr2e3 cDNA was obtained by rapid amplification of cDNA ends (RACE)-PCR using the Smart RACE cDNA kit (BD Biosciences) and total RNA from $55 \mathrm{hr}$ postfertilization (hpf) zebrafish embryos.

Antibodies. Rabbit polyclonal antibodies against the mouse $\mathrm{Nr} 2 \mathrm{e} 3$ (mNr2e3) N-terminal (amino acids 1-39) and linker (amino acids 119208) regions and the $\mathrm{zNr} 2 \mathrm{e} 3 \mathrm{~N}$-terminal (amino acids 1-45) and linker (amino acids 125-239) regions were generated by immunization with T7 gene 10 fusion proteins expressed in Escherichia coli (Studier et al., 1990) and affinity-purified using immobilized glutathione $S$-transferase (GST) fusion proteins carrying the same Nr2e3 sequences. Sera from rabbits immunized with the $\mathrm{T} 7$ gene 10 protein fused to amino acids $126-410$ of $\mathrm{hNr} 2 \mathrm{e} 3$ were affinity-purified using immobilized maltose-binding protein fused to either amino acids $126-221$ or 337-410 of hNr2e3 to give antibodies against the linker region or the C-terminal region, respectively. Other antibodies used were anti- $\beta$-galactosidase and anti-synaptic vesicle protein 2 (SV2) monoclonal antibodies (mAbs) (Developmental Studies Hybridoma Bank, Iowa City, IA); anti-primate cone arrestin mAb 7G6 (Dr. Peter Macleish, Morehouse School of Medicine, Atlanta, GA); anti-zebrafish rhodopsin mAb 1D1 (Dr. James M. Fadool, Florida State University, Tallahassee, FL); anti-rhodopsin mAb 1D4 (Dr. Robert Molday, University of British Columbia, Vancouver, British Columbia, Canada); and rabbit anti-cone transducin $\alpha$ (I-20; Santa Cruz Biotech- nology, Santa Cruz, CA). Rhodamine-conjugated peanut agglutinin was purchased from Vector Laboratories (Burlingame, CA).

Immunostaining. Enucleated mouse eyes were punctured at the cornea and fixed with $1 \%$ paraformaldehyde and PBS at room temperature for 1 $\mathrm{hr}$. The fixed eyes were cryoprotected in PBS with $10 \%$ sucrose at $4^{\circ} \mathrm{C}$ overnight and then embedded in Optimal Cutting Temperature Compound (OCT; Tissue-Tek, Tokyo, Japan). For immunostaining of zebrafish, whole embryonic fish or dissected adult fish eyes were freshfrozen in OCT. Immunostaining of frozen sections was performed essentially as described (Rattner et al., 2001). Whole-mount antibody staining of embryonic zebrafish eyes was performed as described by Luo et al. (2004). Images were captured on a confocal microscope (LSM510; Zeiss, Oberkochen, Germany).

Electrophoretic mobility shift assay. Double-stranded DNA probes containing either of the Nr2e3 binding sites AAGCTTAAGGTCAAAGATCAGGATCC (this study) or AAGCTTTTTAAAAGTCAAAAGTCAACTTCGGATCC (Kobayashi et al., 1999) were ${ }^{32} \mathrm{P}$-end-labeled with the Klenow fragment of DNA polymerase I. Whole-cell extracts were prepared from dissected mouse retinas or 293 cells (mock-transfected or transfected with pRK5/mNr2e3) in extraction buffer (20 mM HEPES pH 7.8, $300 \mathrm{~mm} \mathrm{KCl}, 1 \% \mathrm{NP}-40,20 \%$ glycerol, $0.5 \mathrm{~mm}$ DTT, and a protease inhibitor mixture) at $4^{\circ} \mathrm{C}$ for $2 \mathrm{hr}$. DNA-binding reactions were performed in $20 \mu$ l of binding buffer [20 mM HEPES pH 7.8, $0.3 \mathrm{mg} / \mathrm{ml} \mathrm{BSA}$, $120 \mathrm{~mm} \mathrm{KCl}, 10 \%$ glycerol, $0.1 \% \mathrm{NP}-40,0.5 \mathrm{~mm}$ DTT, and $0.1 \mathrm{mg} / \mathrm{ml}$ poly (dI-dC)] with a 30,000 cpm double-stranded DNA probe and 10-20 $\mu \mathrm{g}$ of protein from the whole-cell extract. For competition experiments, the indicated amount of unlabeled double-stranded competitor DNA was included in the DNA-binding reactions. After incubation at room temperature for $30 \mathrm{~min}$, the protein-DNA complex was resolved on a $5 \%$ polyacrylamide gel in $1 \times$ Tris-borate-EDTA. The gels were subsequently dried and subjected to autoradiography.

In vitro selection of optimal Nr2e3-binding sites. A fusion protein consisting of GST and full-length mNr2e3 was expressed in transfected 293 cells (Tsai and Reed, 1997) and purified on glutathione-Sepharose 4B beads (Amersham Biosciences, Piscataway, NJ). A pool of double-stranded 56 mer oligonucleotides containing a central 20 mer of random sequence flanked by two invariant regions [ATCGATGTCGACAAGCTT(N) ${ }_{20}$ GGATCCGTCGACTCTAGA] was incubated with purified GST-mNr2e3, and the bound species was resolved by electrophoretic mobility shift assay (EMSA) as described above. The gel region corresponding to the proteinDNA complex was excised, and the DNA was eluted in Tris-EDTA. The eluted DNA was PCR-amplified with flanking primers to the invariant regions (upstream, ATCGATGTCGACAAGCTT; downstream, TCTAGAGTCGACGGATCC) for 15 cycles and then used for the next round of EMSA (Thiesen and Bach, 1990; Xiang et al., 1995). After three rounds of selection, the PCR products were digested with HindIII and BamH I and cloned, and individual clones were sequenced.

Cell culture and luciferase assay. A population of 293 cells, maintained in DMEM F-12 supplemented with 10\% charcoal-treated fetal bovine sera (HyClone, Logan, UT), were transfected with $50 \mathrm{ng}$ of expression plasmid, $500 \mathrm{ng}$ of firefly luciferase reporter plasmid, and $10 \mathrm{ng}$ of Renilla luciferase control plasmid (pRL-TK; Promega, San Luis Obispo, CA) using Fugene 6 reagent (Roche Molecular Biochemicals, Indianapolis, IN). Reporter activity was measured using a dual-luciferase report assay system (Promega) $44 \mathrm{hr}$ after transfection.

In situ hybridization. In situ hybridization was performed essentially as described (Schaeren-Wiemers and Gerfin-Moser, 1993). Digoxigeninlabeled riboprobes were transcribed with T7 RNA polymerase from the indicated cDNAs, which were isolated either as cDNA clones or as cloned PCR products derived from mouse eye cDNA. Images were captured on an Axiophot microscope (Zeiss) using Openlab 3.1.2 software.

Microarray hybridization and data analysis. Microarray experiments were performed using mouse genome U74Av2 arrays (Affymetrix, Santa Clara, CA) with retina RNA probes obtained from postnatal day 10 (P10) $r d 7 /+$ and $r d 7 / r d 7$ littermates or from P30 $r d 7 /+$ and $r d 7 / r d 7$ mice. Data from two experiments (four independent RNA samples) at P10 and from three experiments (six independent RNA samples) were used for the analysis. For the triplicate P30 experiment, data were preprocessed using 
robust multichip averaging (Irizarry et al., 2003), converted into a $\log 2$-transformed format, and a $p$ value was calculated for each transcript using $t$ test statistics. Fold changes were calculated from the log2-transformed signal ratios. No scaling factor for variance stabilization or $p$ value correction was used.

RNA preparation and blotting. Retinas from 1- to 2-month-old mice were snap-frozen in dry ice, and RNA was extracted using Trizol (Invitrogen, Carlsbad, CA) and an RNeasy kit (Qiagen, Valencia, CA) following the manufacturers' protocols. RNA blotting was performed using standard methods with ${ }^{32} \mathrm{P}$-labeled cDNA sequences, which were isolated as described under In situ hybridization.

\section{Results}

\section{Nr2e3 sequences and localization} among diverse vertebrates

As an initial step in analyzing Nr2e3 function, we asked whether the Nr2e3 gene is conserved across vertebrates and, if so, whether the expression patterns of the orthologous genes are also conserved. Starting with partial sequences for a presumptive zebrafish (Danio rerio) Nr2e3 ortholog, we used PCR amplification of an adult zebrafish eye cDNA library and RACE-PCR amplification of cDNA prepared from 55 hpf embryos to assemble the translated sequence shown in Figure $1 A$. Comparison of the assembled zebrafish cDNA sequence and the subsequently determined zebrafish genomic sequence corresponding to it shows an intron-exon arrangement nearly identical to that observed for mammalian Nr2e3. The only potential difference is in the location of the first intron, a region where the amino acid sequences do not permit an unambiguous alignment. Further evidence that this zebrafish gene represents a bona fide Nr2e3 ortholog comes from its location close to the HexA, Stoml1, and Cyp11A1 genes, a linkage that is conserved in mouse and human despite an inversion that reverses the order of the mammalian

$N r 2 e 3$ and HexA genes. The currently available zebrafish genome sequence contains no other genes with a comparable degree of sequence similarity to Nr2e3. The pufferfish (Fugu rubripes) genome also appears to encode a single $N r 2 e 3$ ortholog with an intron-exon arrangement similar to that seen among mammalian $\mathrm{Nr} 2 e 3$ genes. A dendrogram comparing presumptive $\mathrm{Nr} 2 e 3$ orthologs from chickens, various mammals, and fish with the most closely related human nuclear hormone receptors reveals a distinct branch of $N r 2 e 3$ sequences (Fig. $1 B$ ). Taken together, these data imply that the $N r 2 e 3$ gene has been maintained as a distinctive member of the nuclear receptor family throughout vertebrate evolution.

Because mutations in NR2E3 appear to affect rod versus short-wave cone identity, a central question is whether $N r 2 e 3$ is expressed exclusively in rods, in both rods and cones, or in rods and a subset of cones. To address this question, we raised rabbit

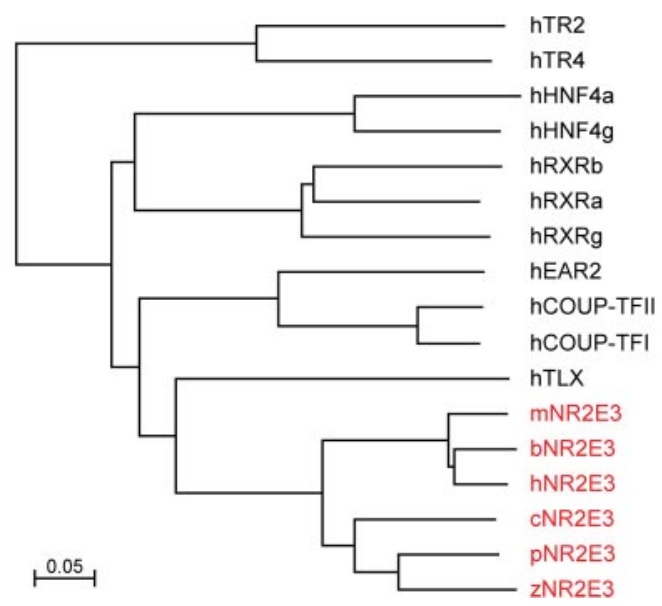

Figure 1. Comparison of Nr2e3 amino acid sequences among diverse vertebrates. A, Alignment of human, mouse, and zebrafish Nr2e3 sequences. Intron positions are shown with downward filled arrowheads. Except for the first intron in the zebrafish used to generate anti-mouse and -zebrafish $\mathrm{Nr} 2 \mathrm{e} 3 \mathrm{~N}$-terminal antibodies. The dashed red underline indicates immunogens used

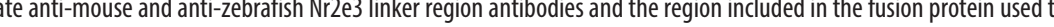
C-terminal and M407K truncation mutants, respectively, studied in human Nr2e3. B. Dendrogram showing the percent amino acid identities among Nr2e3 orthologs from various vertebrates and among the most closely related nuclear receptors from humans. Scale bar, $5 \%$ divergence. b, Bovine; c, chicken; h, human; m, mouse; p, pufferfish (Fugu rubripes); z, zebrafish.

polyclonal antibodies to the linker between the DNA- and ligandbinding domains of $\mathrm{Nr} 2 \mathrm{e} 3$, a region that is moderately conserved among mammalian $\mathrm{Nr} 2 \mathrm{e} 3$ orthologs but has little homology with the most closely related nuclear hormone receptors such as Tlx (Fig. 1A). When macaque retinas were double-labeled for Nr2e3 and cone arrestin [the latter visualized with the primate-specific $\mathrm{mAb} 7 \mathrm{G6}$, which labels the entire cell body of each cone (Zhang et al., 2003)], Nr2e3 was observed in rod but not cone nuclei (Fig. $2 A, B)$. To address the localization of Nr2e3 in the mouse, we took advantage of a cone-specific $\beta$-galactosidase transgene (Wang et al., 1992). Like cone arrestin in the primate retina, $\beta$-galactosidase fills the entire cell body, permitting double-labeling analysis with nuclear Nr2e3. In contrast, most phototransduction proteins, including cone pigments and cone transducin, localize to the outer segment in mature retinas, limiting their utility in double-labeling analyses with nuclear antigens. Double labeling for Nr2e3 and $\beta$-galactosidase in 

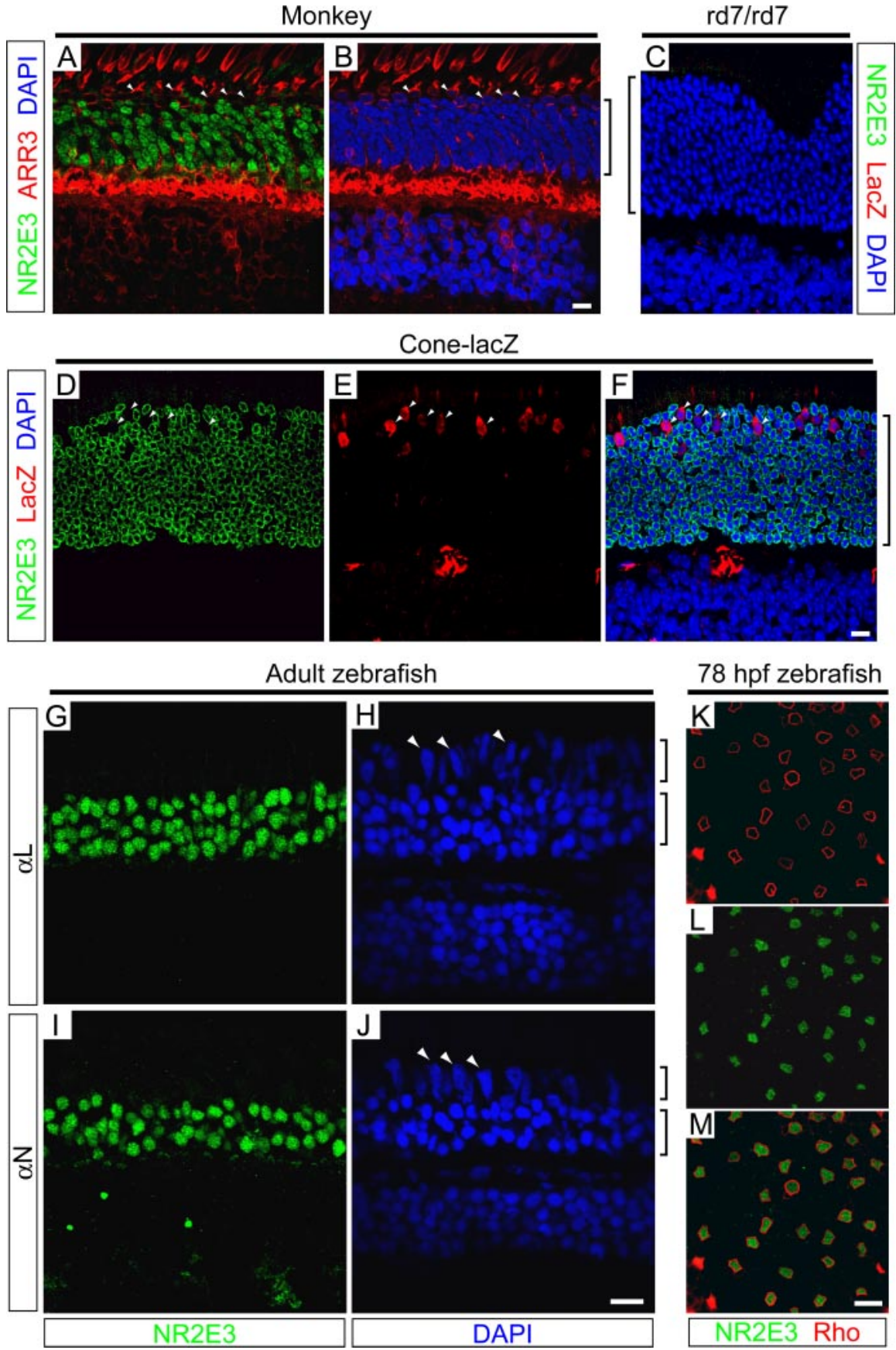

Figure 2. Immunolocalization of Nr2e3 to rod photoreceptors in monkey, mouse, and zebrafish retinas. $A, B$, Macaque retina immunostained for Nr2e3 and cone arrestin (ARR3; mAb 7G6) and counterstained with 4',6-diamidino-2-phenylindole (DAPI). $(-F, r d 7 / r d 7(C)$ and transgenic cone- $\beta$ galactosidase $(D-F)$ mouse retinas immunostained for $N r 2 \mathrm{e} 3$ and $\beta$-galactosidase and counterstained with DAPI. The specificities of $\mathrm{mNr} 2 \mathrm{e} 3$ and $\beta$-galactosidase antibodies are demonstrated by the absence of immunostaining in the nontransgenic $r d 7 / r d 7$ retina. The large red object in the outer plexiform layer in $E$ and $F$ is a blood vessel in which intravascular mouse lgG is stained with the Alexa594-conjugated anti-mouse secondary antibody. G-J, Zebrafish retinas immunostained with antibodies to amino acids $1-45(\alpha \mathrm{N})$ and $125-239(\alpha \mathrm{L})$ of zNr2e3 and counterstained with DAPI. K-M, Flat mount of zebrafish retina at $78 \mathrm{hpf} \mathrm{immunostained} \mathrm{for} \mathrm{rhodopsin} \mathrm{and} \mathrm{Nr2e} 3$ shows that, in the central retina at this time point, $\mathrm{Nr2e} 3$ is observed exclusively in rods. In each of the species examined, Nr2e3 immunostaining is confined to rod nuclei; cone nuclei $(A, B, D-F, H, J$, white arrowheads) do not contain Nr2e3. Brackets adjacent to $B, C$, and $F$ indicate the outer nuclear layer; brackets adjacent to $\mathrm{H}$ and $J$ indicate the cone (top bracket) and rod (bottom bracket) nuclear layers. Scale bars, $10 \mu \mathrm{m}$. retina is demonstrated by their absence from a nontransgenic $r d 7 / r d 7$ retina (Fig. $2 C$ ).

To extend these observations to a more distant vertebrate, antibodies against two distinct regions of zebrafish Nr2e3 (Fig. $1 A)$ were used to immunostain zebrafish retinas. Immunostaining of the adult retina, in which rod nuclei are spatially segregated from cone nuclei and occupy only the inner half of the outer nuclear layer, shows that $N r 2 e 3$ is expressed exclusively in rods (Fig. $2 G-J$ ). The rod specificity of $\mathrm{Nr} 2 \mathrm{e} 3$ localization is also observed in retinal flat mounts by double labeling with anti-zebrafish rhodopsin $\mathrm{mAb}$ 1D1 (Fig. $2 \mathrm{~K}-\mathrm{M})$. At $78 \mathrm{hpf}, \sim 2 \mathrm{~d}$ after the birth of most rod and cone photoreceptors, there is sufficient rhodopsin in rod cell bodies to use it as a marker for double labeling with a nuclear antigen.

\section{$\mathrm{Nr} 2 \mathrm{e} 3$ is expressed in rod precursors}

The hypothesized role of Nr2e3 in controlling gene expression in rod photoreceptors predicts that Nr2e3 expression should precede the expression of those gene products that characterize the fully differentiated state. Rhodopsin is one of the earliest markers of rod differentiation, and in the developing mouse retina, as in the developing zebrafish retina, it initially accumulates in the cell bodies of immature rods. Double immunostaining for rhodopsin and Nr2e3 at P3 and P6 shows the expected time-dependent increase in the number of developing rods (Fig. $3 A-F$ ). However, at each of these time points, rhodopsin-expressing cells constitute only a subset of the Nr2e3-positive cells. This can be seen most clearly at P6, when recently postmitotic cells in the future inner nuclear layer commit to a rod fate and migrate outward to their final destination in the outer nuclear layer (Young, 1984). Whereas Nr2e3 accumulates in the nuclei of premigratory rod precursors, rhodopsin accumulation is generally observed only after the cells migrate to their final destination in the outer nuclear layer (Fig. $3 D-H)$. The junction between the developing inner and outer nuclear layers is identified by the accumulation of SV2 in the developing outer plexiform layer (Fig. $3 G-J)$. At P14, after the period of rod precursor migration, Nr2e3 immunolabeling is confined to the outer nuclear layer (Fig. $3 I, J)$. The accumulation of $\mathrm{Nr} 2 \mathrm{e} 3$ in presumptive photoreceptor precursors begins the transgenic retina shows that $\mathrm{Nr} 2 \mathrm{e} 3$ is confined to rod nuclei (Fig. $2 D-F)$. In the mouse retina, $\mathrm{Nr} 2 \mathrm{e} 3$ immunostaining is most intense near the nuclear periphery, the region where the chromatin appears to be least condensed (Carter-Dawson and LaVail, 1979). The specificity of $\mathrm{Nr} 2 \mathrm{e} 3$ and $\beta$-galactosidase immunostaining in the mouse at least as early as embryonic day 18 (E18), when small numbers of Nr2e3-stained nuclei are seen in the outer retina (data not shown); at all developmental stages, Nr2e3 immunoreactivity localizes to the nucleus.

A more complex pattern of $N r 2 e 3$ expression is seen in the 
developing zebrafish retina. At $2 \mathrm{~d}$ postfertilization (dpf), a time point immediately after the birth of many cone and rod photoreceptors and before the accumulation of detectable levels of visual pigment, $\mathrm{Nr} 2 \mathrm{e} 3$ transcripts and Nr2e 3 protein accumulate in most, and perhaps all, developing photoreceptors as judged by the high density of labeled cells (Fig. 4A,C). However, by $4 \mathrm{dpf}, \mathrm{Nr} 2 \mathrm{e} 3$ immunostaining in the central retina is restricted to scattered rod photoreceptors (Figs. $2 K-M, 4 C, D$ ), a spatial and temporal pattern previously described for developing rods (Fadool, 2003); these cells populate the photoreceptor mosaic over the ensuing several days. In the less mature retinal periphery at 4 dpf, Nr2e3-expressing cells are present at high density and therefore are likely to include cone precursors. These data suggest that in zebrafish, Nr2e3 may play a transient role in early cone photoreceptor development.

\section{Optimal Nr2e3-binding sites mediate transcriptional repression in transfected cells}

In earlier studies, Kobayashi et al. (1999) demonstrated the binding of expressed human Nr2e3 to a synthetic DNA target designed on the basis of a naturally occurring site for the related Drosophila protein Tailless. To define the optimal binding site(s) for $\mathrm{Nr} 2 \mathrm{e} 3$ in an unbiased manner, we used repeated cycles of in vitro selection to isolate a family of synthetic duplex DNA targets from a library of DNA segments of random sequence (Thiesen and Bach, 1990). The synthetic DNA library was incubated with a purified GST fusion to fulllength mouse Nr2e 3 that was expressed in 293 cells, and the bound DNA targets were enriched by EMSA. After three rounds of binding and PCR amplification, an alignment of the sequences of 23 cloned sites yielded the consensus 5'-(A/G)AG(A/G)TCAAA(A/G)(A/G)TCA (Fig. 5A).

The core binding site for nonsteroid nuclear hormone receptors is the hexamer $A G(G / T) T C A$, and the binding specificity of different receptor dimers is determined by the orientation and spacing of pairs of hexamers (for review, see Arannda and Pascual, 2001). Based on these observations, we presume that Nr2e3 binds to the optimal site as a dimer. The optimal Nr2e3 site appears to include sequence constraints outside the core hexamers because the first and eighth bases (i.e., the bases preceding the first and second hexamers) were strongly biased to A/G and A, respectively. Substitutions of either $\mathrm{C}$ or $\mathrm{T}$ in the first position of the optimal site decreased the efficiency of EMSA binding by $>10$-fold (data not shown).

Binding to a consensus DNA duplex site (AAAGTCAAAAGTCA) was demonstrated by EMSA using mNr2e 3 expressed in 293 cells (Fig. 5B). The shifted species is presumed to represent an mNr2e3-DNA complex because it is absent from untransfected 293 cells, and it can be supershifted by antibodies against the linker region of hNr2e3 but not by irrelevant antibodies. Anti-
P3

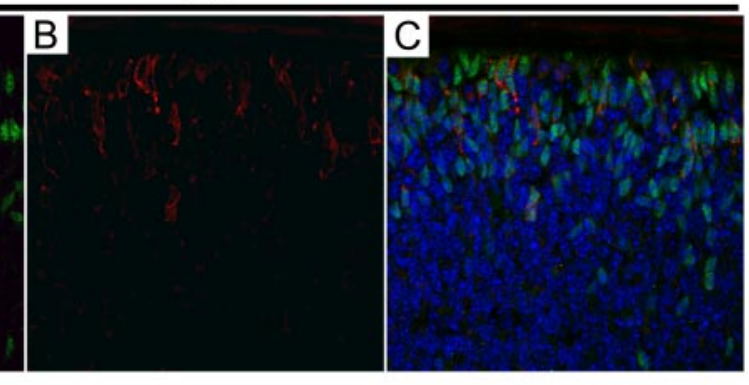

P6

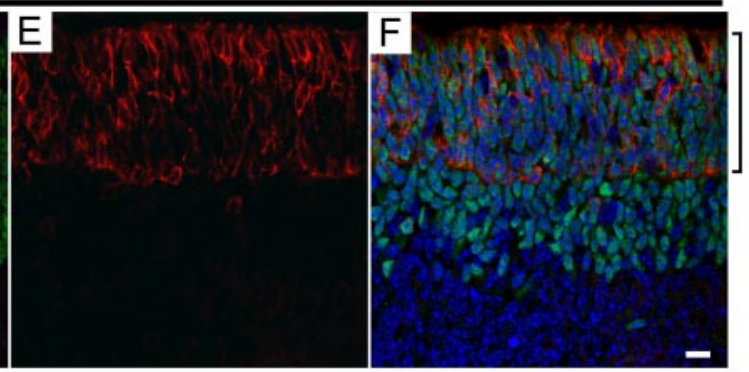

P6
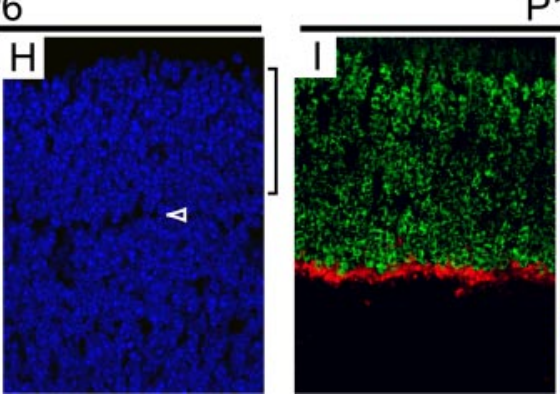

P14

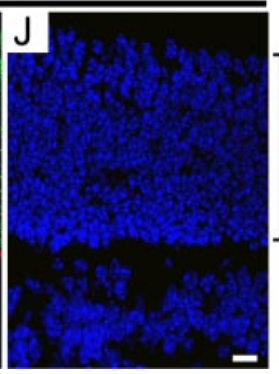

Figure 3. Nr2e3 accumulates in rod precursors in the developing mouse retina. $A-F, \mathrm{P} 3(A-C)$ and $\mathrm{P} 6(D-F)$ mouse retinas immunostained for Nr2e3 and rhodopsin and counterstained with DAPI. $G-J, P 6(G, H)$ and P14 $(I, J)$ mouse retinas immunostained for Nr2e3 and SV2 and counterstained with DAPI. Only the outer half of each retina, containing the future inner and oute indicate the developing outer plexiform layer. All rhodopsin-containing cells also contain Nr2e3, but additional cells, presumably early rod precursors, contain Nr2e3 but do not contain rhodopsin. Scale bars, $10 \mu \mathrm{m}$.

bodies to the C-terminal 73 amino acids also fail to supershift, presumably because these antibodies were generated against denatured protein and fail to bind native mNr2e3. Expressed human and zebrafish Nr2e3 exhibit similar binding and supershifting behavior in the EMSA (data not shown).

A protein-DNA complex between the Nr2e3 consensus site AAGGTCAAAGATCA and mNr2e3 was also observed using extracts from mouse retina (Fig. $5 C$ ). The authenticity of this complex is inferred from (1) its absence when extracts were prepared from $r d 7 / r d 7$ retinas, (2) its disruption (or conversion to an electrophoretically heterogeneous species) on addition of antihNr2e3 linker region antibodies but not irrelevant antibodies, and (3) its indistinguishable electrophoretic mobility relative to the complex formed by mNr2e3 expressed in 293 cells. The specificity of $\mathrm{mNr} 2 \mathrm{e} 3$ for the consensus DNA target was further confirmed by competition with unlabeled DNA (Fig. 5C). The specificity of the antilinker antibodies used in these experiments for $\mathrm{mNr} 2 \mathrm{e} 3$ is shown in the immunoblot in Figure $5 C$, which also demonstrates the expected absence of $\mathrm{Nr} 2 \mathrm{e} 3$ protein in $r d 7 / r d 7$ retina extracts.

The effect of mNr2e3 on the transcription of a minimal herpes simplex virus thymidine kinase promoter carrying two, four, or 
2dpf
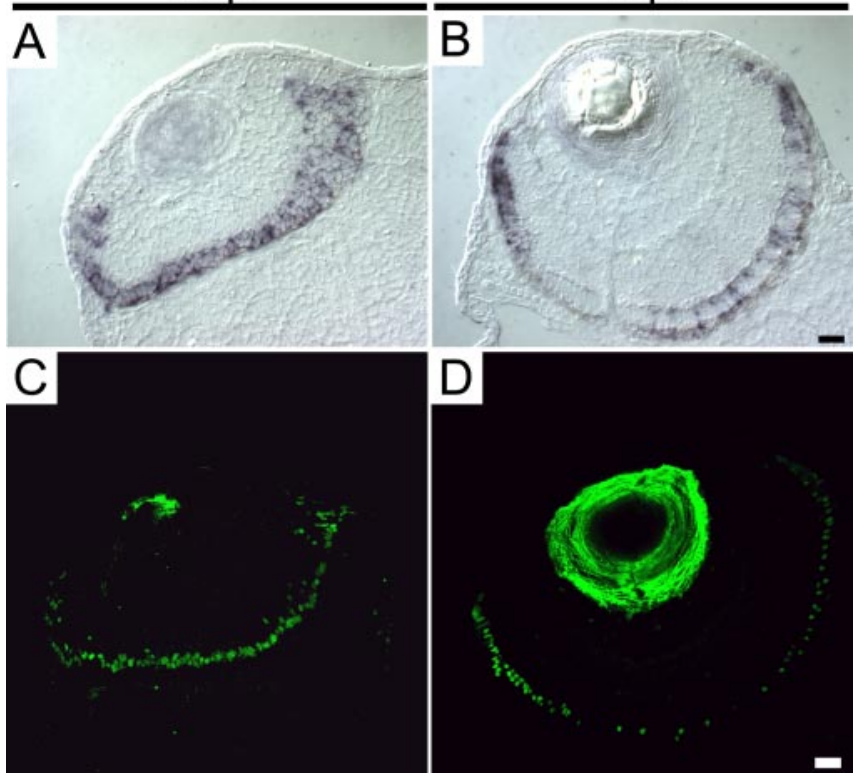

Figure 4. Transient Nr2e3 expression in cones in the developing zebrafish retina. In situ hybridization $(A, B)$ and immunostaining $(C, D)$ for Nr2e3 at 2 and 4 dpf is shown. Immunostaining of the lens is nonspecific. Cells throughout the photoreceptor layer are stained at $2 \mathrm{dpf}$, but only rods express $\mathrm{Nr2e} 3$ in the most mature (central) region of the retina at $4 \mathrm{dpf}$. Scale bars, $20 \mu \mathrm{m}$.

no copies of the Nr2e3 consensus binding site was determined by transient cotransfection in 293 cells (Fig. 5D). This experiment shows that $\mathrm{mNr} 2 \mathrm{e} 3$ represses the basal activity of the luciferase reporter and that repression is more effective in the presence of additional Nr2e3 consensus binding sites, independent of their orientation. If this transcriptional repression is mediated by the binding of corepressors to the $\mathrm{Nr} 2 \mathrm{e} 3$ ligand-binding domain (LBD), as seen for other nuclear hormone receptors, then it should be observed when this domain alone is localized to the target promoter. Chen et al. (1999) demonstrated this property of Nr2e3 by cotransfecting a plasmid coding for the Gal4 DNAbinding domain (DBD) fused to the Nr2e3 LBD and a plasmid carrying a reporter controlled by a promoter containing Gal4binding sites. We have confirmed this finding and additionally observed that mutations in the hNr2e3 LBD that either eliminate the predicted C-terminal helix or introduce an M407K substitution, a mutation associated with the enhanced S-cone syndrome (Haider et al., 2000), mostly abolish transcriptional repression (Fig. 5E). These data are consistent with structural data from other nuclear hormone receptors showing that the C-terminal helix of the LBD plays a critical role in the corepressor complex (Perissi et al., 1999; Ghosh et al., 2002; Xu et al., 2002).

\section{Accumulation of cone-specific transcripts in $r d 7 / r d 7$ retinas}

As described in the Introduction, electrophysiologic and anatomic analyses of Nr2e3-deficient retinas in humans and mice suggest that Nr2e3 normally acts to repress the development of $\mathrm{S}$-cones. To define the action of Nr2e3 at the level of gene regulation, we used in situ hybridization to analyze the expression patterns of a series of cone- and rod-specific genes in the retinas of $r d 7 /+$ and $r d 7 / r d 7$ littermates before significant photoreceptor cell loss (Fig. 6). [With respect to retinal histology, the $r d 7$ mutation appears to be fully recessive, and therefore we have used wild-type (WT) and $r d 7 /+$ retinas as equivalent representatives of the normal retina.]

This analysis shows that the distribution and abundance of
A

$\begin{array}{lrrrrrrrrrrrrrr}\text { position } & \mathbf{1} & \mathbf{2} & \mathbf{3} & \mathbf{4} & \mathbf{5} & \mathbf{6} & \mathbf{7} & \mathbf{8} & \mathbf{9} & \mathbf{1 0} & \mathbf{1 1} & \mathbf{1 2} & \mathbf{1 3} & \mathbf{1 4} \\ \mathbf{G} & 11 & 5 & 16 & 13 & 0 & 0 & 0 & 2 & 0 & 14 & 14 & 0 & 0 & 0 \\ \mathbf{A} & 9 & 17 & 3 & 9 & 0 & 0 & 23 & 19 & 23 & 8 & 8 & 0 & 0 & 23 \\ \mathbf{T} & 1 & 0 & 1 & 1 & 23 & 1 & 0 & 2 & 0 & 1 & 1 & 23 & 2 & 0 \\ \mathbf{C} & 2 & 1 & 3 & 0 & 0 & 22 & 0 & 0 & 0 & 0 & 0 & 0 & 21 & 0 \\ \text { total } & 23 & 23 & 23 & 23 & 23 & 23 & 23 & 23 & 23 & 23 & 23 & 23 & 23 & 23 \\ \text { consensus } & \mathbf{a} / \mathbf{g} & \mathbf{A} & \mathbf{G} & \mathbf{a} / \mathbf{g} & \mathbf{T} & \mathbf{C} & \mathbf{A} & \mathbf{A} & \mathbf{A} & \mathbf{a} / \mathbf{g} & \mathbf{a} / \mathbf{g} & \mathbf{T} & \mathbf{C} & \mathbf{A}\end{array}$

B
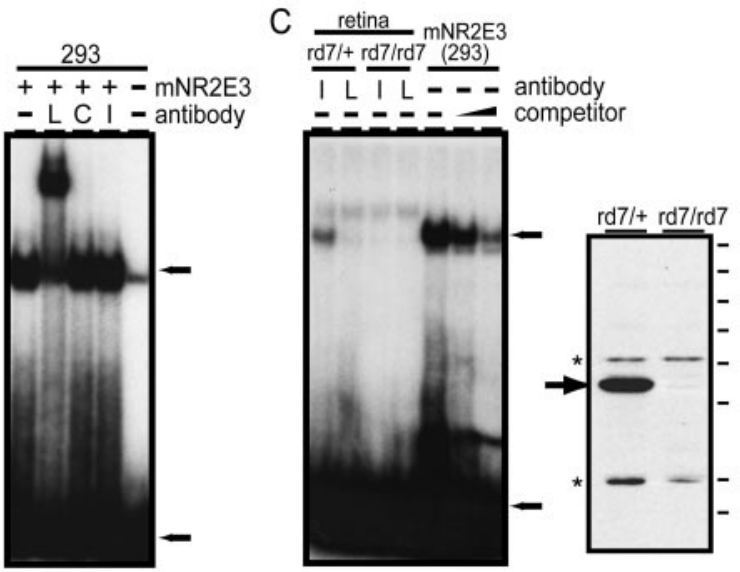

D
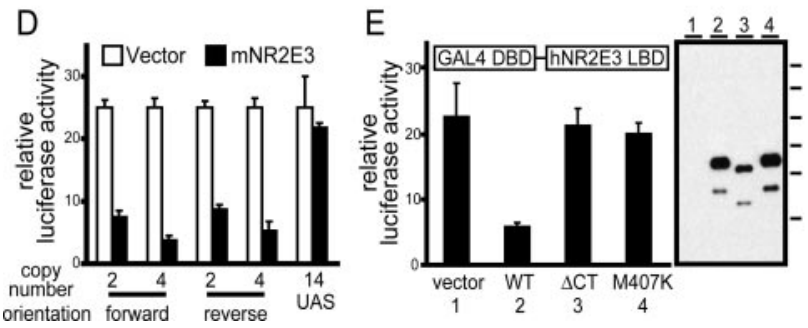

Figure 5. An optimal Nr2e3-binding site mediates Nr2e3-dependent transcriptional repression in transfected cells. $A$, Compilation of 23 cloned oligonucleotide sequences after three rounds of selection with a GST fusion to full-length $\mathrm{mNr2e} 3$. $B$, EMSA with mNr2e3 produced in transfected 293 cells using the DNA duplex probe defined by Kobayashi et al. (1999) (see Materials and Methods). Antibodies directed against the hNr2e3 linker region $(\mathrm{L})$ produce a supershift; antibodies directed against the C-terminal 73 amino acids of hNr2e3 (C) or against an irrelevant protein (photoreceptor cadherin; I) do not produce a mobility shift. Extracts from untransfected 293 cells (-) produce a weak EMSA band that has a slightly higher electrophoretic mobility than that produced by mNr2e3. C, Left panel, EMSA using an optimal DNA duplex probe determined by in vitro selection (see Materials and Methods). Left four lanes, EMSA using retina extracts from $r d 7 /+$ or $r d 7 / r d 7$ littermates incubated with anti-hNr2e3 linker region or irrelevant antibodies. Right three lanes, EMSA with mNr2e3 produced in transfected 293 cells in the presence of increasing quantities ( 0.5 and $2.5 \mu \mathrm{m}$ ) of the same optimal DNA duplex as competitor. Top and bottom arrows, Bound and free probe, respectively. Right panel, Specificity of the anti-hNr2e3 linker region antibodies used for supershifting experiments determined by immunoblotting of retina proteins from $r d 7 /+$ or $r d 7 / r d 7$ littermates. Arrow, Nr2e3; asterisks, cross-reacting proteins. Molecular mass standards (from top to bottom): 183, $114,81,64,50,37,26$, and $20 \mathrm{kDa}$. D, Cotransfection of 293 cells with a vector (pRK5) directing the expression of full-length $\mathrm{mNr2e} 3$ or with pRK5 alone, together with a luciferase reporter under the control of a minimal herpes simplex virus thymidine kinase promoter $3^{\prime}$ of the indicated number and orientation of optimal $\mathrm{Nr2e}$-binding sites determined by in vitro selection. A control reporter carries $14 \mathrm{Gal} 4$ UAS sites in place of the Nr2e3 sites. Nr2e3 represses expression in a target-site-dependent manner. $E$, Cotransfection of 293 cells with pRK5 directing the expression of a Gal4DBD- $\mathrm{hNr2e} 3 \mathrm{LBD}$ fusion protein together with a luciferase reporter under the control of a minimal herpes simplex virus thymidine kinase promoter $3^{\prime}$ of 14 tandem Gal4 UAS sites. The hNr2e3 LBD corresponds to amino acids $126-410$. Repression of the reporter is seen with the WT Nr2e3 LBD sequence but not with a C-terminal truncation of 13 amino acids $(\Delta C T)$, substitution mutation M407K, or empty pRK5 vector. Right panel, Immunoblot of the different Gal4-Nr2e3LBD constructs expressed in 293 cells with anti-hNr2e3 antibodies. Lanes 1- 4 refer to the four numbered samples in the graph. Each fusion protein shows similar levels of cleavage between the Gal4 and Nr2e3 domains, producing a lower-molecular weight Nr2e3LBD polypeptide. Molecular mass standards (from top to bottom): 183, 114, 81, 64, 50, and $37 \mathrm{kDa}$. Error bars in $D$ and $E$ indicate SDs of at least three experiments. 
three rod-specific transcripts, rhodopsin, the $\alpha$ subunit of rod cGMP phosphodiesterase (Pde6a), and the $\alpha$ subunit of rod transducin (Gnat1), are unaltered in the $r d 7 / r d 7$ retina (Fig. $6 A-C$ ), as is the distribution and abundance of $\mathrm{Nrl}$ transcripts (Fig. 6D). Consistent with the anti-Nr2e3 immunostaining shown in Figure 2, we observe $\mathrm{Nr} 2 \mathrm{e} 3$ transcripts confined to the outer nuclear layer in both WT and $r d 7 / r d 7$ retinas (Fig. 6M,N). Interestingly, the Nr2e3 hybridization signal is $\sim 10$-fold stronger in $r d 7 / r d 7$ retinas compared with WT retinas, an observation discussed more fully below.

This analysis also reveals two distinct patterns of aberrant accumulation of cone-specific transcripts in the $r d 7 / r d 7$ retina. One pattern of aberrant transcript accumulation is most evident in the inferior retina, where S-cones are most highly concentrated. Here, transcripts coding for S-opsin, cone arrestin (Arr3), and the $\beta$ subunit of the cone cyclic nucleotidegated channel (Cngb3) accumulate in cells in the outer third of the outer nuclear layer, the normal location for cone cell bodies, as well as in a class of cells of approximately comparable abundance scattered throughout the inner two-thirds of the outer nuclear layer (Fig. $6 E-G$ ). A similar pattern is likely to hold for the $\alpha$ subunit of the cone cyclic nucleotide-gated channel (Cnga3) and the $\gamma$ subunit of cone transducin (Gngt2), but the low signals observed with these transcripts make an unambiguous determination difficult (data not shown). We will refer to these additional cells as inner cones. In the superior retina, in situ hybridization with the $\mathrm{S}$-opsin probe shows that inner S-cones decrease in abundance approximately in proportion to the decrease in the abundance of normally positioned S-cones (Fig. 6O). In contrast to S-opsin transcripts, M-opsin transcripts remain confined to the outer third of the outer nuclear layer in the adult (Fig. $6 H$ ); they were the only cone-specific transcripts that showed a normal pattern of localization in the adult $r d 7 / r d 7$ retina. However, during late retinal development (P14), M-opsin transcripts transiently localize to both normally positioned cones and inner cones in the $r d 7 / r d 7$ retina (Fig. $6 P$ ), whereas in age-matched $r d 7 /+$ littermates, they are confined to the outer aspect of the outer nuclear layer (data not shown). This analysis also shows that the retinal folds that characterize the $r d 7 / r d 7$ retina reflect a general spreading out and buckling of the outer nuclear layer (Fig. 6E,F) rather than a local enrichment of excess cones, as suggested by Haider et al. (2001).

A second pattern of abnormal transcript accumulation is seen with the $\alpha$ and $\beta$ subunits of cone transducin (Gnat2 and Gnb3)
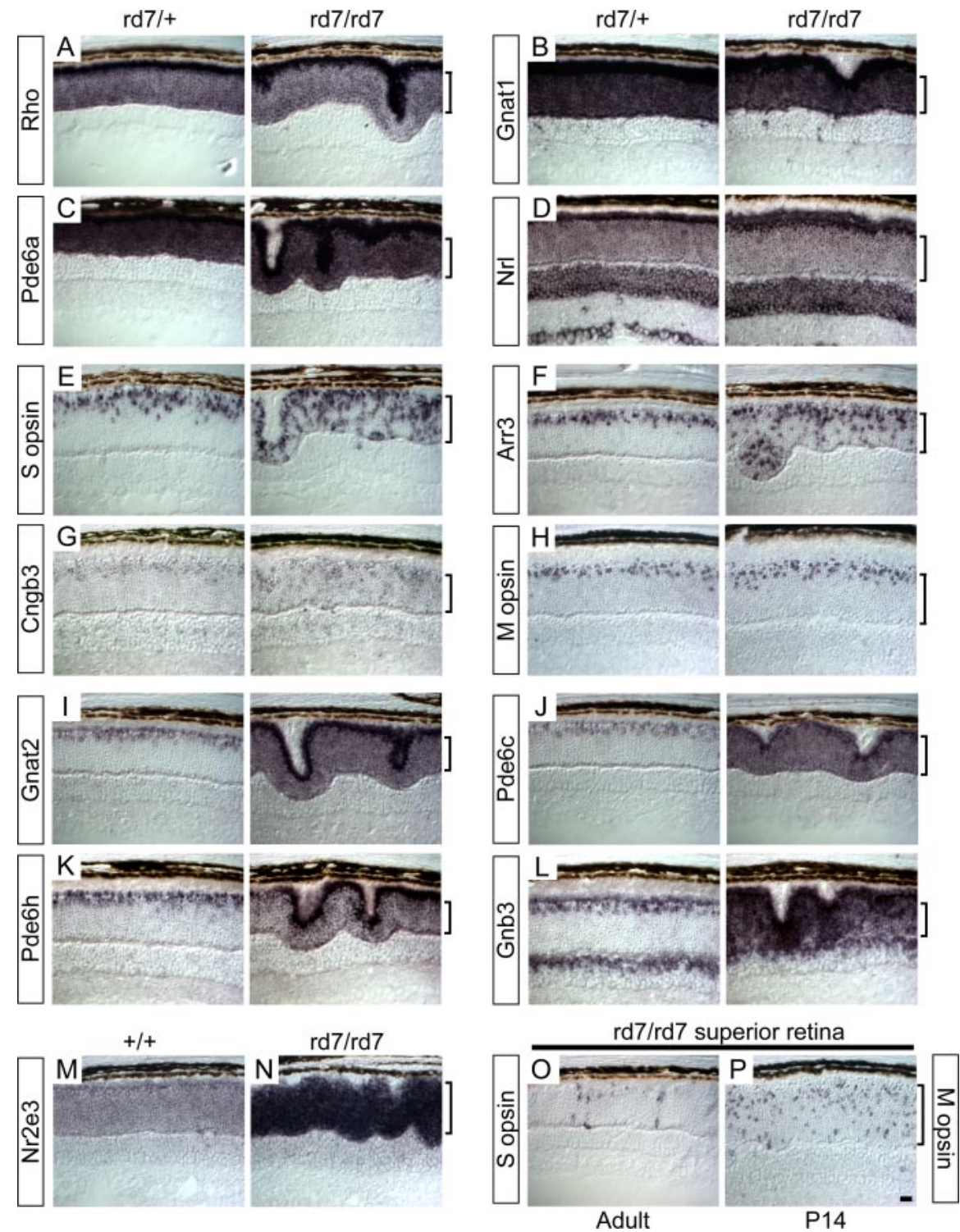

Figure 6. In situ hybridization reveals distinct patterns of cone-specific gene expression in $r d 7 / r d 7$ retinas. $A-L$, In situ hybridization to retinas obtained from 6-week-old $r d 7 /+$ (left) or $r d 7 / r d 7$ (right) littermates with probes for the indicated rod and cone transcripts. $A-D$, Rod transcripts with no detectable alteration in expression in the $r d 7 / r d 7$ retina. $E-H$, Cone transcripts that are mostly excluded from rods in both $r d 7 /+$ and $r d 7 / r d 7$ retinas. $I-L$, Cone transcripts that are expressed in rods in the $r d 7 / r d 7$ retina. The sections with $\mathrm{S}$-opsin $(E)$ and $\mathrm{M}$-opsin $(H)$ hybridizations are derived from inferior and superior retina, respectively, the regions with the highest concentrations of $S$ - and $M$-cones. $M, N$, Hybridization to 6 -week-old $+/+$ and $r d 7 / r d 7$ retinas with an Nr2e3 probe. $0, P$, Superior region of $r d 7 / / r d 7$ retinas at the indicated ages hybridized with S-opsin (left) or M-opsin (right) probes. As in the WT retina, $S$-cones are present at low density in the superior half of the $r d 7 / r d 7$ retina, but in the $r d 7 / r d 7$ retina, they reside in both normal and abnormal (i.e., inner) regions of the outer nuclear layer (ONL). In the $r d 7 / r d 7$ retina, $\mathrm{M}$-cone cell bodies are initially found throughout the $0 \mathrm{NL}$, and this distribution progressively shifts to the outer edge of the $0 \mathrm{NL}$, as seen by comparing M-opsin hybridization patterns at P14 versus 6 weeks $(P, H)$. Each panel shows the full thickness of the retina, with the retinal pigment epithelium at the top and the ganglion cell layer at the bottom. The vertical brackets indicate the extent of the ONL. Characteristic retinal folds are seen in the $r d 7 / r d 7$ sections, but the relative composition of photoreceptor cell types does not appear to differ between folded and normal regions of the retina. For each probe, the pair of sections of different genotypes was processed on the same slide; therefore, relative signal intensities directly reflect differences in transcript abundance. Chromogenic substrate development times differed among probes. Scale bar, $20 \mu \mathrm{m}$.

and the $\alpha$ and $\gamma$ subunits of the cone cGMP phosphodiesterase (Pde6c and Pde6h) (Fig. 6I-L). For each of these transcripts, loss of Nr2e3 leads to a dramatic accumulation in rods, as determined by the hybridization signal across the outer nuclear layer. Figure $6 L$ shows that the $\beta$ subunit of cone transducin is also normally expressed in a subset of neurons in the inner nuclear layer. Some rod transcripts, such as those encoding rhodopsin (Fig. 6A) and 
A
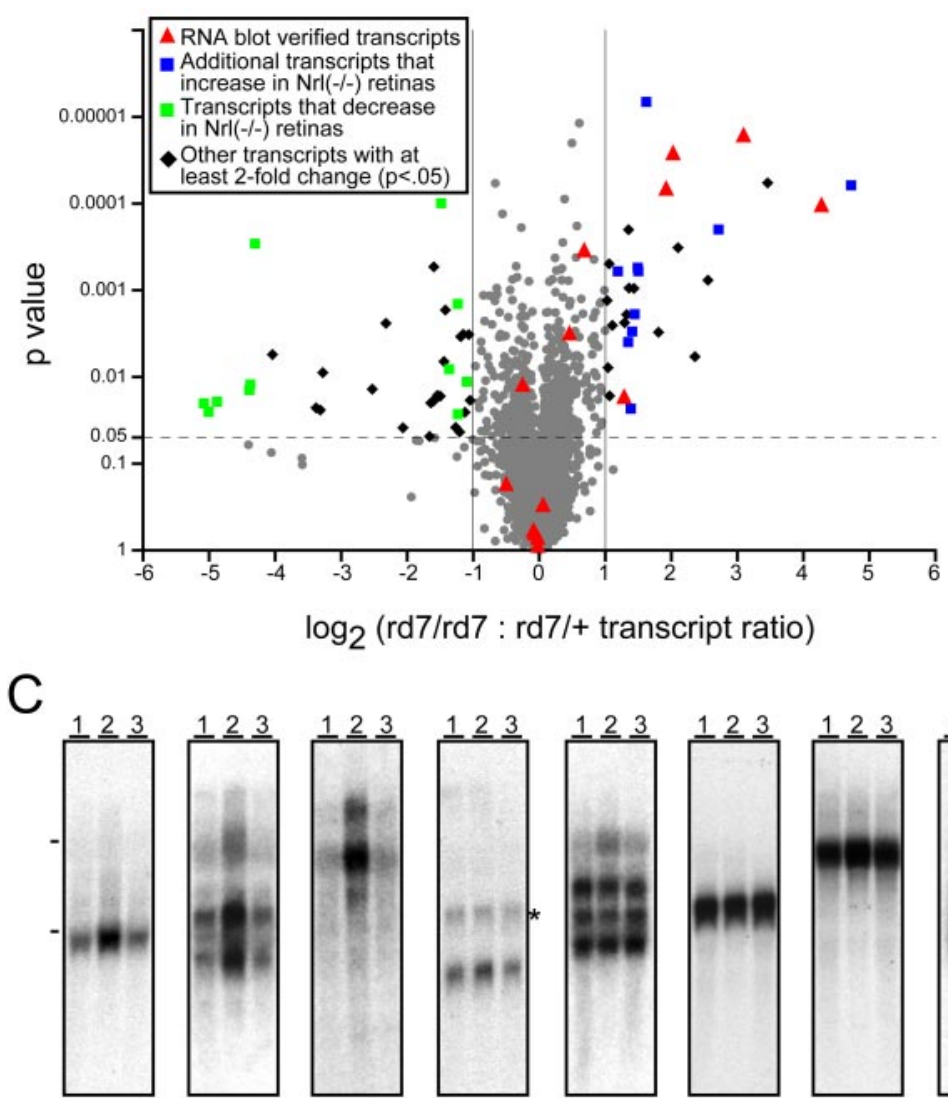

S opsin

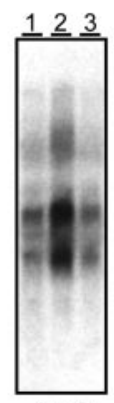

Arr3

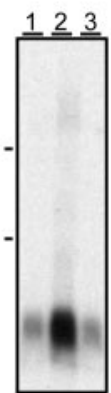

Pde6h

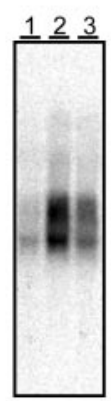

Gnb3

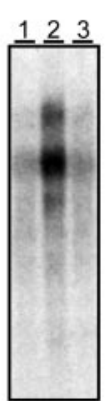

Cngb3 M opsin

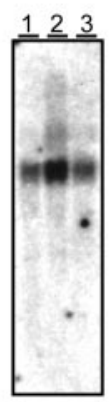

Cnga3
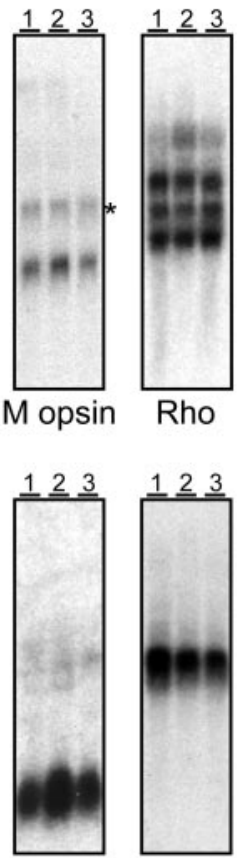

Gngt2

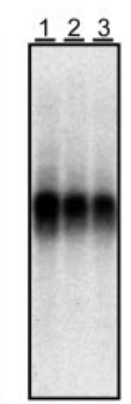

$\mathrm{Nrl}$

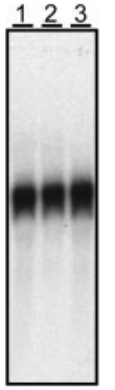

Gnat1

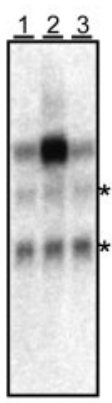

Elovl2
$\mathrm{B}$

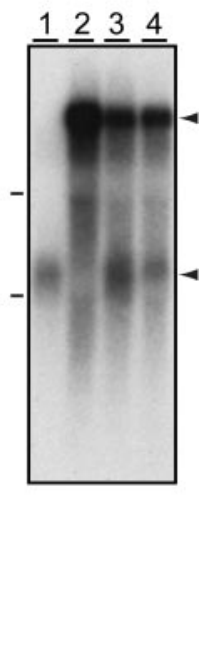

of S-cone-like cells in the inner two-thirds of the outer nuclear layer.

Microarray and RNA blot hybridization

To obtain a global assessment of the changes in gene expression in the $r d 7 / r d 7$ retina, retina RNA was prepared from P10 $r d 7 /+$ or $r d 7 / r d 7$ littermates and from P30 $r d 7 /+$ or $r d 7 / r d 7$ mice and hybridized to the Affymetrix U74Av2 chip, which analyzes $\sim 12,500$ mouse transcripts. The scatterplot in Figure $7 A$ summarizes the comparison of $r d 7 / r d 7: r d 7 /+$ transcript ratios at P30 for three independent RNA preparations; similar changes in transcript abundance were observed with $\mathrm{P} 10$ retinas (data not shown). For the vast majority of transcripts with detectable hybridization signals, the absence of Nr2e 3 causes little or no change in abundance. A number of transcripts encoding crystallins are present at appreciable levels in the $r d 7 /+$ RNA samples; these transcripts could be retinaderived (Xi et al., 2003), or they might reflect variable contamination with small amounts of lens epithelium. In agreement with the in situ hybridization results described above, the abundances of several cone-specific transcripts are consistently higher in the $r d 7 / r d 7$ retina. An additional set of transcripts correspond to a set that were recently reported to be altered in abundance in the $\mathrm{Nrl}(-/-)$ retina (Yoshida et al., 2004), and these are also consistently altered in the same manner in the $r d 7 / r d 7$ retina. These include transcripts for the Clca3 chloride channel, fatty acidbinding protein 7 ( Fabp 7 ), and a presumptive long-chain fatty acid synthase (Elovl2). $r d 7 / r d 7$ retinas show little or no change in the levels of transcripts coding for rod phototransduction proteins, in contrast to the downregulation of these transcripts seen in $\mathrm{Nrl}(-/-)$ retinas (Yoshida et al., 2004). A summary of the changes in transcript abundance in the $r d 7 / r d 7$ retina is given in supplemental Table 1 (available at www.jneurosci.org as supplemental material).

To independently confirm the results of in situ and microarray hybridization and to compare transcript abundances between the $r d 7 / r d 7$ retina and a retina with a similarly slow but mechanistically unrelated degeneration, RNA blots were prepared from 1- to 2-month-old WT, $r d 7 /$

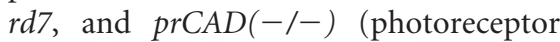
cadherin) retinas (Rattner et al., 2001) at ages before substantial photoreceptor loss. As seen in Figure 7C, RNA blotting confirms the elevation of
transcripts coding for S-opsin, cone arrestin, the $\alpha$ and $\beta$ subunits of cone transducin (Gnat2 and Gnb3), and the $\alpha$ and $\gamma$

subunits of the cone cGMP phosphodiesterase (Pde6c and

the aberrantly expressed $\alpha$ subunit of cone transducin in the $r d 7 / r d 7$ retina (Fig. $6 I$ ), are enriched in the inner segment region of rod photoreceptors. Thus, loss of Nr2e3 leads both to a derepression of many cone-specific genes in rods and the production 
Pde6h) in $r d 7 / r d 7$ retinas. The elevation of Gnat2, Pde6c, and Pde6h transcripts is especially dramatic, consistent with their accumulation in rod photoreceptors seen by in situ hybridization (Fig. $6 H-J$ ). RNA blotting also reveals a modest elevation of transcripts coding for the $\alpha$ subunit of the cone cGMP-gated channel (Cnga3) and the cone-specific $\gamma$ subunit of transducin (Gngt2), consistent with their expression in both normal and inner cones in $r d 7 / r d 7$ retinas. Importantly, the levels of these transcripts are not elevated in the $\operatorname{prCAD}(-/-)$ retina, implying that this pattern of transcript accumulation is not a general response to progressive photoreceptor degeneration. For each of the photoreceptor-specific transcripts, RNA blot hybridization also shows no elevation in the $r d s / r d s$ retina (data not shown). Also consistent with the microarray hybridization analysis, RNA blotting shows an elevation of Fabp7 and Elovl2 transcripts in $r d 7 / r d 7$ retinas (Fig. $7 C$ ). These transcripts code, respectively, for a high-affinity docosahexanoic acid (DHA)-binding protein (Xu et al., 1996) and an elongase that synthesizes long-chain polyunsaturated fatty acids, including DHA (Leonard et al., 2002), suggesting that $\mathrm{Nr} 2 \mathrm{e} 3$ plays a role in controlling the metabolism of this class of lipids.

Finally, we investigated the levels of $N r 2 e 3$ transcripts in $r d 7 / r d 7$ and $\operatorname{prCAD}(-/-)$ retinas and observed the accumulation of a novel high-molecular weight $N r 2 e 3$ transcript specifically in $r d 7 /$ $r d 7$ retinas at levels manyfold higher than that of the normal Nr2e3 transcript in WT retinas (Fig. $7 B$ ). [This observation is at odds with a previous report showing no $N r 2 e 3$ transcripts in the $r d 7 / r d 7$ retina (Akhmedov et al., 2000).] The high-molecular weight $\mathrm{Nr} 2 \mathrm{e} 3$ transcript is also abundant in $r d 7 /+$ retinas, and, interestingly, the normal Nr2e3 transcript is more abundant in the $r d 7 /+$ retina than in the WT retina (Fig. $7 B$ ). The high-molecular weight $N r 2 e 3$ transcript also hybridizes to a probe from intron 5 (data not shown). We note that the accumulation of a partially spliced mutant transcript is highly unusual because most transcripts of this type are efficiently eliminated by nonsensemediated RNA decay (Frisch-meyer and Dietz, 1999). Taken together, these data suggest the possibility that Nr2e3 normally feedback-inhibits the production of its own transcripts, and the $r d 7 /+$ heterozygote displays haploinsufficiency, or, less likely, protein (or RNA) products of the $r d 7$ allele may dominantly interfere with that inhibition in both $r d 7 /+$ and $r d 7 / r d 7$ retinas.

\section{Cone transducin in $r d 7 / r d 7$ rod outer segments}

In $r d 7 / r d 7$ rods, the high level of transcripts encoding cone phototransduction proteins suggests that some or all of these proteins might be present at substantial levels in rod outer segments. To test this possibility for the $\alpha$ subunit of cone transducin (Gnat2), retinas from $r d 7 /+$ and $r d 7 / r d 7$ littermates were immunostained with an antipeptide antibody that specifically recognizes this protein and also stained with peanut agglutinin (PNA), which labels the extracellular matrix sheath surrounding all cone outer segments (Fig. 8). In the $r d 7 /+$ retina, cone $\alpha$-transducin is confined to cones, as expected (Fig. $8 A-C$ ). In contrast, in the $r d 7 / r d 7$ retina, cone $\alpha$-transducin is present in both rod and cone outer segments, a pattern that is most clearly seen in the superior retina where the cone density is lower than in the inferior retina (Fig. $8 D-L)$. In both the superior and inferior retina, the intensity of rod outer segment immunostaining is somewhat lower than that of cone outer segments. These data suggest that $r d 7 / r d 7$ mice, and by inference $N r 2 e 3(-/-)$ humans, use a mixture of rod and cone proteins for rod phototransduction.

\section{Discussion}

Implications of $\mathrm{Nr} 2 \mathrm{e} 3$ conservation and rod expression In this study, we show that $N r 2 e 3$ orthologs are present in diverse vertebrates, including fish and mammals, suggesting that $N r 2 e 3$ 
arose in concert with the evolution of rod and cone photoreceptors. In keeping with this evolutionary history, our observations regarding $\mathrm{Nr} 2 \mathrm{e} 3$ expression in rods and the effects of the $\mathrm{Nr} 2 \mathrm{e} 3$ mutation in the mouse retina point to a central role for $\mathrm{Nr} 2 \mathrm{e} 3$ in orchestrating the patterns of gene expression that distinguish rod and cone photoreceptors.

In mature primate, mouse, and zebrafish retinas, $\mathrm{Nr} 2 \mathrm{e} 3$ is localized exclusively to the nuclei of all rods. In early development in the mouse, Nr2e 3 accumulates in rod precursors before the appearance of rhodopsin, making Nr2e3 one of the earliest markers of rod precursors. Consistent with the data reported here, O'Brien et al. (2004) have recently reported that Nr2e3 expression is excluded from developing cones in the fetal human retina. In contrast, in zebrafish there appears to be a transient wave of Nr2e3 expression in developing cone photoreceptors before the onset of cone pigment gene expression.

\section{Gene expression defects in the $\mathrm{rd} / \mathrm{rd} 7$ retina}

By in situ, microarray, and RNA blot hybridization, we observe a highly selective pattern of gene expression defects in the $r d 7 / r d 7$ retina. Several cone-specific transcripts, including the S-opsin message, are expressed in abnormally located cells within the outer nuclear layer, which we have termed inner cones; numerous cone-specific transcripts are aberrantly expressed in rods; and rod transcripts are unaltered in pattern and abundance, except for the high level of an aberrant Nr2e3 transcript. Thus, conespecific genes show a fundamental division into two classes based on their responses to loss of $\mathrm{Nr} 2 \mathrm{e} 3$. None of the above-mentioned alterations are observed in a mechanistically unrelated retinal degeneration caused by loss of photoreceptor cadherin, and microarray analysis indicates that most transcripts are unaltered in the $r d 7 / r d 7$ retina. These data, together with the observation that $\mathrm{Nr} 2 \mathrm{e} 3$ functions as a transcriptional repressor in transfected cells (Chen et al., 1999; this study), suggest that one principal function of Nr2e3 is to repress the expression of cone-specific genes in rods. The observation of modestly elevated levels of the WT $N r 2 e 3$ transcript in $r d 7 /+$ retinas further suggests the possibility that Nr2e3 may directly or indirectly act in a negative feedback loop to regulate the levels of its own transcript.

Haider et al. (2001) described a 1.5- to 2-fold increase in the number of $S$-cones in the $r d 7 / r d 7$ retina using peanut agglutinin staining and anti-S-opsin immunostaining, and our in situ hybridization analyses suggest that this excess can be accounted for mostly or entirely by the inner S-cones. To explain this excess of $\mathrm{S}$-cones in mice and the even greater excess of $\mathrm{S}$-cones in humans with Nr2e3 mutations, several groups have suggested that Nr2e3 might function as a repressor of S-cone proliferation (Haider et al. 2001; Milam et al., 2002). This explanation would be most plausible if, as in zebrafish, $N r 2 e 3$ was transiently expressed in mammalian cone precursors and could regulate cone proliferation in a cell-autonomous manner. Alternatively, the observations that $\mathrm{Nr} 2 e 3$ is expressed in rods but not cones in mammalian retinas and that many cone-specific transcripts are derepressed in $r d 7 / r d 7$ rods suggest that the $N r 2 e 3(-/-)$ phenotype in both mice and humans might be explained strictly as a defect in gene regulation in postmitotic cells. In this conceptualization, all rods in the $r d 7 / r d 7$ retina are somewhat cone-like in their gene expression patterns. The inner S-cones may represent a subset of photoreceptors that were initially destined for a rod fate but became de facto cones by activating a sufficiently large number of conespecific genes. This discussion highlights the difficulties associated with using the terms rod and cone when, as in the $r d 7 / r d 7$ retina, the patterns of gene expression, which constitute the op-

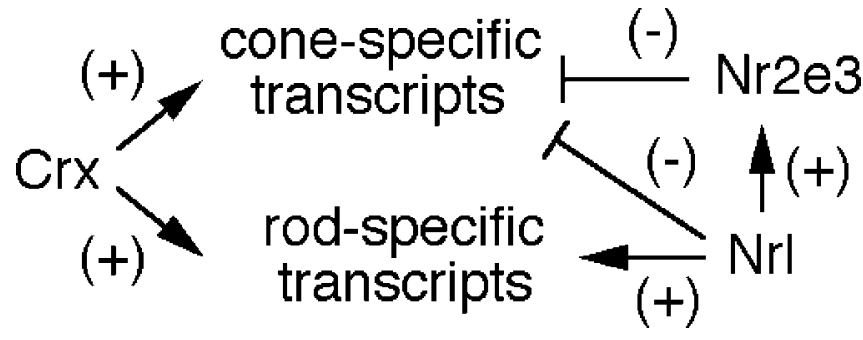

Figure 9. Model for transcriptional control in rod photoreceptors. Crx activates the transcription of both rod- and cone-specific genes (Furukawa et al., 1999), and Nrl activates the transcription of rod-specific genes, including Nr2e3 (Mears et al., 2001). Both Nrl (Mears et al., 2001) and Nr2e3 repress the transcription of cone-specific genes. In the mouse retina, Crx transcripts appear at $\sim$ E12.5 (Furukawa et al., 1997), Nrl transcripts appear at $\sim$ E14.5 (Liu et al., 1996), and Nr2e3 transcripts appear at $\sim$ E16.5 (Cheng et al., 2004), suggesting a temporal hierarchy with $\mathrm{Crx}$ and $\mathrm{Nrl}$ above $\mathrm{Nr2e} 3$.

erational distinction between cell types, are altered to produce intermediate types.

\section{The role of $\mathrm{Nr} 2 \mathrm{e} 3$ in controlling photoreceptor gene expression}

The $r d 7 / r d 7$ defects reported here are reminiscent of some of the defects observed in $\mathrm{Nrl}(-/-)$ retinas (Mears et al., 2001). However, $\mathrm{Nrl}(-/-)$ retinas show a more extreme transformation of rods toward a cone-like fate, including an absence of transcripts coding for rhodopsin, rod transducin $\alpha$, and rod cGMP phosphodiesterase $\beta$ and a large increase in S-opsin transcripts. Because $\mathrm{Nrl}(-/-)$ retinas also lack $\mathrm{Nr} 2 e 3$ transcripts, it is likely that all of the molecular defects seen in the $r d 7 / r d 7$ retina are included in the $\mathrm{Nrl}(-/-)$ phenotype. Figure 9 presents a diagram showing the relationship among $\mathrm{Crx}, \mathrm{Nrl}$, and $\mathrm{Nr2e} 3$ in controlling rodand cone-specific genes in rod photoreceptor cells. Crx activates various rod- and cone-specific genes (Furukawa et al., 1999), and $\mathrm{Nrl}$ activates the transcription of various rod-specific genes, including Nr2e3 (Mears et al., 2001). Both Nrl (Mears et al., 2001) and $\mathrm{Nr} 2 \mathrm{e} 3$ repress the transcription of cone-specific genes. It would be interesting to determine whether a symmetric system exists in cones for repressing rod-specific genes.

Recent in vitro and cell culture experiments suggest that $\mathrm{Nr} 2 \mathrm{e} 3$ may interact with the nuclear hormone receptor Nr1d1 (Reverb- $\alpha$ ) to synergistically activate the rhodopsin and rod transducin $\alpha$ promoters (Cheng et al., 2004). In contrast, our cell culture analyses with full-length Nr2e3 and with Gal4DBD-Nr2e3LBD fusions have shown only transcriptional repression. However, our cell culture experiments should be interpreted cautiously because they are at best suggestive of $\mathrm{Nr} 2 \mathrm{e} 3$ function on the relevant target promoters, in rod photoreceptors, and in the presence of interacting partners and/or small molecule ligands. We note, however, that our failure to see significant alterations in rod transcripts in the $r d 7 / r d 7$ retina suggest that, if the transcriptional activation postulated by Cheng et al. (2004) also occurs in the retina, it is subject to compensatory regulation in the absence of $\mathrm{Nr} 2 \mathrm{e} 3$.

\section{Implications for $\mathrm{Nr} 2 \mathrm{e} 3$-associated retinal diseases}

NR2E3 mutations were first identified in patients with the enhanced S-cone syndrome, but more recent work has shown that NR2E3 mutations are a common cause of clumped pigmentary retinopathy in the context of enhanced S-cone syndrome, Goldman-Favre syndrome, and retinitis pigmentosa (Sharon et al., 2003). In one postmortem study, the pigmentary clumps seen ophthalmoscopically were shown to correspond to large num- 
bers of melanin granules within retinal pigment epithelial cells (To et al., 1996), suggesting the possibility that the retinal degeneration caused by NR2E3 mutations may occur in a distinctive spatial pattern. Enhanced S-cone syndrome is characterized by reduced rod, $\mathrm{L}$-cone, and $\mathrm{M}$-cone responses, an early disorganization of retinal lamination, and a progressive loss of photoreceptors (Jacobson et al., 1990, 2004; Haider et al., 2000). Abnormal patterns of cone photoreceptor immunoreactivity have also been described in a postmortem study of one late-stage enhanced S-cone syndrome retina (Milam et al., 2002; Cideciyan et al., 2003).

In the $r d 7 / r d 7$ retina, the increase in the total number of S- but not $\mathrm{M}$-cones and the progressive loss of rod photoreceptors appear to faithfully model the human disease process. The misexpression of numerous cone transcripts in $r d 7 / r d 7$ rods suggests that rod loss in patients with NR2E3 mutations may arise from the toxic consequences of gene misexpression. It would be of interest to determine whether phototransduction is altered in $r d 7 / r d 7$ rods as a consequence of this misexpression. It is also intriguing that transcripts coding for two proteins implicated in long-chain polyunsaturated fatty acid metabolism, Fabp7 and Elovl2, are induced. Photoreceptor outer segments contain unusually high levels of DHA and other long-chain polyunsaturated fatty acids (Penn and Anderson, 1987), and DHA levels in rod outer segments decline in diverse models of inherited retinal degeneration, which has led several groups to suggest that decreased DHA may be a protective response to retinal degeneration (Penn and Anderson, 1987; Anderson et al., 2001; Bicknell et al., 2002). Moreover, mutations in a gene coding for a presumptive fatty acid elongase, Elovl4, cause an autosomal dominant macular degeneration (Edwards et al., 2001; Zhang et al., 2001). Thus, retinal degeneration in patients with NR2E3 mutations might also be caused, at least in part, by aberrant metabolism of long-chain fatty acids.

\section{References}

Akhmedov NB, Piriev NI, Chang B, Rapoport AL, Hawes NL, Nishina PM, Nusinowitz S, Heckenlively JR, Roderick TH, Kozak CA, Danciger M, Davisson MT, Farber DB (2000) A deletion in a photoreceptor-specific nuclear receptor mRNA causes retinal degeneration in the rd7 mouse. Proc Natl Acad Sci USA 97:5551-5556.

Anderson RE, Maude MB, Bok D (2001) Low docosahexaenoic acid levels in rod outer segment membranes of mice with rds/peripherin and P216L peripherin mutations. Invest Ophthalmol Vis Sci 42:1715-1720.

Arannda A, Pascual A (2001) Nuclear hormone receptors and gene expression. Physiol Rev 81:1269-1304.

Bessant DA, Payne AM, Mitton KP, Wang QL, Swain PK, Plant C, Bird AC, Zack DJ, Swaroop A, Bhattacharya SS (1999) A mutation in NRL is associated with autosomal dominant retinitis pigmentosa. Nat Genet 21:355-356.

Bicknell IR, Darrow R, Barsalou L, Fliesler SJ, Organisciak DT (2002) Alterations in retinal rod outer segment fatty acids and light-damage susceptibility in $\mathrm{P} 23 \mathrm{H}$ rats. Mol Vis 8:333-340.

Carter-Dawson LD, LaVail MM (1979) Rods and cones in the mouse retina: structural analysis using light and electron microscopy. J Comp Neurol 188:245-262.

Chen F, Figueroa DJ, Marmorstein AD, Zhang Q, Petrukhin K, Caskey CT, Austin CP (1999) Retina-specific nuclear receptor: a potential regulator of cellular retinaldehyde-binding protein expressed in retinal pigment epithelium and Muller glial cells. Proc Natl Acad Sci USA 96:15149-15154.

Chen S, Wang QL, Nie Z, Sun H, Lennon G, Copeland NG, Gilbert DJ, Jenkins NA, Zack DJ (1997) Crx, a novel Otx-like paired-homeodomain protein, binds to and transactivates photoreceptor cell-specific genes. Neuron 19:1017-1030.

Cheng H, Khanna H, Oh EC, Hicks D, Mitton KP, Swaroop A (2004) Photoreceptor-specific nuclear receptor NR2E3 functions as a transcriptional activator in rod photoreceptors. Hum Mol Genet 13:1563-1575.
Cideciyan AV, Jacobson SG, Gupta N, Osawa S, Locke KG, Weiss ER, Wright AF, Birch DG, Milam AH (2003) Cone deactivation kinetics and GRK1/ GRK7 expression in enhanced S cone syndrome caused by mutations in NR2E3. Invest Ophthalmol Vis Sci 44:1268-1274.

Edwards AO, Donoso LA, Ritter R (2001) A novel gene for autosomal dominant Stargardt-like macular dystrophy with homology to the SUR4 protein family. Invest Ophthalmol Vis Sci 42:2652-2663.

Fadool JM (2003) Development of a rod photoreceptor mosaic revealed in transgenic zebrafish. Dev Biol 258:277-290.

Freund CL, Gregory-Evans CY, Furukawa T, Papaioannou M, Looser J, Ploder L, Bellingham J, Ng D, Herbrick JA, Duncan A, Scherer SW, Tsui LC, Loutradis-Anagnostou A, Jacobson SG, Cepko CL, Bhattacharya SS, McInnes RR (1997) Cone-rod dystrophy due to mutations in a novel photoreceptor-specific homeobox gene (CRX) essential for maintenance of the photoreceptor. Cell 91:543-553.

Frischmeyer PA, Dietz HC (1999) Nonsense-mediated mRNA decay in health and disease. Hum Mol Genet 8:1893-1900.

Furukawa T, Morrow EM, Cepko CL (1997) Crx, a novel otx-like homeobox gene, shows photoreceptor-specific expression and regulates photoreceptor differentiation. Cell 91:531-541.

Furukawa T, Morrow EM, Li T, Davis FC, Cepko CL (1999) Retinopathy and attenuated circadian entrainment in Crx-deficient mice. Nat Genet 23:466-470.

Gerber S, Rozet JM, Takezawa SI, dos Santos LC, Lopes L, Gribouval O, Penet C, Perrault I, Ducroq D, Souied E, Jeanpierre M, Romana S, Frezal J, Ferraz F, Yu-Umesono R, Munnich A, Kaplan J (2000) The photoreceptor cell-specific nuclear receptor gene (PNR) accounts for retinitis pigmentosa in the Crypto-Jews from Portugal (Marranos), survivors from the Spanish Inquisition. Hum Genet 107:276-284.

Ghosh JC, Yang X, Zhang A, Lambert MH, Li H, Xu HE, Chen JD (2002) Interactions that determine the assembly of a retinoid $\mathrm{X}$ receptor/corepressor complex. Proc Natl Acad Sci USA 99:5842-5847.

Haider NB, Jacobson SG, Cideciyan AV, Swiderski R, Streb LM, Searby C, Beck G, Hockey R, Hanna DB, Gorman S, Duhl D, Carmi R, Bennett J, Weleber RG, Fishman GA, Wright AF, Stone EM, Sheffield VC (2000) Mutation of a nuclear receptor gene, NR2E3, causes enhanced S cone syndrome, a disorder of retinal cell fate. Nat Genet 24:127-131.

Haider NB, Naggert JK, Nishina PM (2001) Excess cone cell proliferation due to lack of a functional NR2E3 causes retinal dysplasia and degeneration in rd7/rd7 mice. Hum Mol Genet 10:1619-1626.

Irizarry RA, Bolstad BM, Collin F, Cope LM, Hobbs B, Speed TP (2003) Summaries of Affymetrix GeneChip probe level data. Nucleic Acids Res 31:e15.

Jacobson SG, Marmor MF, Kemp CM, Knighton RW (1990) SWS (blue) cone hypersensitivity in a newly identified retinal degeneration. Invest Opthalmol Vis Sci 31:827-838.

Jacobson SG, Sumaroka A, Aleman TS, Cideciyan AV, Schwartz SB, Roman AJ, McInnes RR, Sheffield VC, Stone EM, Swaroop A, Wright AF (2004) Nuclear receptor NR2E3 gene mutations distort human retinal laminar architecture and cause an unusual degeneration. Hum Mol Genet 13:1893-1902.

Kobayashi M, Takezawa S, Hara K, Yu RT, Umesono Y, Agata K, Taniwaki M, Yasuda K, Umesono K (1999) Identification of a photoreceptor cellspecific nuclear receptor. Proc Natl Acad Sci USA 96:4814-4819.

Leonard AE, Kelder B, Bobik EG, Chuang LT, Lewis CJ, Kopchick JJ, Mukerji $P$, Huang YS (2002) Identification and expression of mammalian longchain PUFA elongation enzymes. Lipids 37:733-740.

Liu Q, Ji X, Breitman ML, Hitchcock PF, Swaroop A (1996) Expression of the bZIP transcription factor gene $\mathrm{Nrl}$ in the developing nervous system. Oncogene 12:207-211.

Luo W, Williams J, Smallwood PM, Touchman JW, Roman LM, Nathans J (2004) Proximal and distal sequences control UV cone pigment gene expression in transgenic zebrafish. J Biol Chem 279:19286-19293.

Mears AJ, Kondo M, Swain PK, Takada Y, Bush RA, Saunders TL, Sieving PA, Swaroop A (2001) $\mathrm{Nrl}$ is required for rod photoreceptor development. Nat Genet 29:447-452.

Milam AH, Rose L, Cideciyan AV, Barakat MR, Tang WX, Gupta N, Aleman TS, Wright AF, Stone EM, Sheffield VC, Jacobson SG (2002) The nuclear receptor NR2E3 plays a role in human retinal photoreceptor differentiation and degeneration. Proc Natl Acad Sci USA 99:473-478.

Ng L, Hurley JB, Dierks B, Srinivas M, Salto C, Vennstrom B, Reh TA, Forrest 
D (2001) A thyroid hormone receptor that is required for the development of green cone photoreceptors. Nat Genet 27:94-98.

O'Brien KM, Cheng H, Jiang Y, Schulte D, Swaroop A, Hendrickson AE (2004) Expression of photoreceptor-specific nuclear receptor NR2E3 in rod photoreceptors of fetal human retina. Invest Ophthalmol Vis Sci 45:2807-2812.

Penn JS, Anderson RE (1987) Effect of light history on rod outer-segment membrane composition in the rat. Exp Eye Res 44:767-778.

Perissi V, Staszewski LM, McInerney EM, Kurokawa R, Krones A, Rose DW, Lambert MH, Milburn MV, Glass CK, Rosenfeld MG (1999) Molecular determinants of nuclear receptor-corepressor interaction. Genes Dev 13:3198-3208.

Rattner A, Smallwood PM, Williams J, Cooke C, Savchenko A, Lyubarsky A, Pugh EN, Nathans J (2001) A photoreceptor-specific cadherin is essential for the structural integrity of the outer segment and for photoreceptor survival. Neuron 32:775-786.

Rodieck RW (1998) The first steps in seeing. Sunderland, MA: Sinauer.

Schaeren-Wiemers N, Gerfin-Moser A (1993) A single protocol to detect transcripts of various types and expression levels in neural tissue and cultured cells: in situ hybridization using digoxigenin-labelled cRNA probes. Histochemistry 100:431-440.

Sharon D, Sandberg MA, Caruso RC, Berson EL, Dryja TP (2003) Shared mutations in NR2E3 in enhanced S-cone syndrome, Goldmann-Favre syndrome, and many cases of clumped pigmentary retinal degeneration. Arch Ophthalmol 121:1316-1323.

Studier FW, Rosenberg AH, Dunn JJ, DubendorffJW (1990) Use of T7 RNA polymerase to direct expression of cloned genes. Methods Enzymol 185:60-89.

Swain PK, Chen S, Wang QL, Affatigato LM, Coats CL, Brady KD, Fishman GA, Jacobson SG, Swaroop A, Stone E, Sieving PA, Zack DJ (1997) Mutations in the cone-rod homeobox gene are associated with the cone-rod dystrophy photoreceptor degeneration. Neuron 19:1329-1336.

Thiesen HJ, Bach C (1990) Target detection assay (TDA): a versatile procedure to determine DNA binding sites as demonstrated on SP1 protein. Nucleic Acids Res 18:3203-3209.

Tsai RY, Reed RR (1997) Using a eukaryotic GST fusion vector for proteins difficult to express in E. coli. Biotechniques 23:794-800.

To KW, Adamian M, Jakobiec FA, Berson EL (1996) Clinical and his- topathologic findings in clumped pigmentary retinal degeneration. Arch Ophthalmol 114:950-955.

Wang Y, Macke JP, Merbs SL, Zack DJ, Klaunberg B, Bennett J, Gearhart J, Nathans J (1992) A locus control region adjacent to the human red and green visual pigment genes. Neuron 9:429-440.

Yanagi Y, Takezawa S, Kato S (2002) Distinct functions of photoreceptor cell-specific nuclear receptor, thyroid hormone receptor beta2 and CRX in cone photoreceptor development. Invest Ophthalmol Vis Sci 43:3489-3494.

Yoshida S, Mears AJ, Friedman JS, Carter T, He S, Oh E, Jing Y, Farjo R, Fleury G, Barlow C, Hero AO, Swaroop A (2004) Expression profiling of the developing and mature $\mathrm{Nrl}-/-$ mouse retina: identification of retinal disease candidates and transcriptional regulatory targets of $\mathrm{Nrl}$. Hum Mol Genet 13:1487-1503.

Young RW (1984) Cell death during differentiation of the retina in the mouse. J Comp Neurol 229:362-373.

Xi J, Farjo R, Yoshida S, Kern TS, Swaroop A, Andley UP (2003) A comprehensive analysis of the expression of crystallins in mouse retina. Mol Vis 9:410-419.

Xiang M, Zhou L, Macke JP, Yoshioka T, Hendry SH, Eddy RL, Shows TB, Nathans J (1995) The Brn-3 family of POU-domain factors: primary structure, binding specificity, and expression in subsets of retinal ganglion cells and somatosensory neurons. J Neurosci 15:4762-4785.

Xu HE, Stanley TB, Montana VG, Lambert MH, Shearer BG, Cobb JE, McKee DD, Galardi CM, Plunket KD, Nolte RT, Parks DJ, Moore JT, Kliewer SA, Willson TM, Stimmel JB (2002) Structural basis for antagonistmediated recruitment of nuclear co-repressors by PPARalpha. Nature 415:813-817.

Xu LZ, Sanchez R, Sali A, Heintz N (1996) Ligand specificity of brain lipidbinding protein. J Biol Chem 271:24711-24719.

Zhang H, Cuenca N, Ivanova T, Church-Kopish J, Frederick JM, MacLeish PR, Baehr W (2003) Identification and light-dependent translocation of a cone-specific antigen, cone arrestin, recognized by monoclonal antibody 7G6. Invest Ophthalmol Vis Sci 44:2858-2867.

Zhang K, Kniazeva M, Han M, Li W, Yu Z, Yang Z, Li Y, Metzker ML, Allikmets R, Zack DJ, Kakuk LE, Lagali PS, Wong PW, MacDonald IM, Sieving PA, Figueroa DJ, Austin CP, Gould RJ, Ayyagari R, Petrukhin K (2001) A 5-bp deletion in ELOVL4 is associated with two related forms of autosomal dominant macular dystrophy. Nat Genet 27:89-93. 